\title{
Ex Utero Intrapartum Treatment (Exit) of Gigantic Intrapartum Lymphangioma and Its Management Dilemma - A Case Report
}

\author{
Dev Bir Intrapartum Lenfanjiyomunun Ex Utero Intrapartum Tedavisi \\ (Exit) ve Yönetim Íkilemi - Bir Vaka Sunumu
}

\section{Ren Hui LO $\odot$, Nik Khairani Nik MOHD $\odot$, Khairudin ABDULLAH $\odot$, Azliana AZIZ $\odot$, Irfan MOHAMAD $\odot$}

Ethics Committee Approval: Not Applicable.

Conflict of Interest: The authors declare that they have no conflict of interest.

Funding: None.

Informed Consent: Informed consent was obtained.
Cite as: Ren HUI Lo RH, Mohd NKN, Abdullah K, Aziz A, Mohamad I. Ex utero intrapartum treatment (exit) of gigantic intrapartum lymphangioma and its management dilemma - A case report. Medeniyet Med J. 2020;35:161-5.

\begin{abstract}
With the advancement of radiological investigation, intrapartum detection of fetal abnormalities is now precisely performed. Lymphangiomas are now diagnosed even before patient is born. The swelling may be gigantic and potentially life-threatening during the delivery. Nowadays, it is still a great challenge to doctors as how to deliver the baby together with the big neck mass. We present a case of huge intrapartum neck lymphangioma, for which we performed ex-utero intrapartum treatment (EXIT) procedure, followed by excision of the lesion later. The challenges on managing both mother and infant will be discussed.
\end{abstract}

Keywords: Lymphangioma, parturition, uterus

öz

Radyolojik incelemelerin ilerlemesiyle birlikte, fetal anormalliklerin intrapartum tespiti günümüzde tam olarak yapılmaktadır. Lenfanjiyomlar artık hasta doğmadan önce dahi teşhis edilmektedir. Şişme büyük ölçekli olabilir ve potansiyel açıdan doğum sırasında hayatı tehdit edici olabilir. Bugün bile bebeğin doğumunun büyük ölçekte bir boyun kütlesiyle birlikte nasıl gerçekleştirileceği konusu doktorlar için büyük bir zorluktur. Ex-utero intrapartum tedavi (EXIT) prosedürünü uyguladığımız ve daha sonra lezyonun eksizyonunu yaptığımız büyük boyutlu bir intrapartum boyun lenfanjiyomu olgusu sunuyoruz. Hem annenin hem de bebeğin yönetimindeki zorluklar tartışılmış̦tır.

Anahtar kelimeler: Lenfanjiyom, doğum, uterus
Received: 18 February 2020

Accepted: 30 April 2020

Online First: 30 June 2020

\section{Corresponding Author:}

A. Aziz

ORCID: 0000-0002-6750-5797

Universiti Sains Malaysia,

School of Medical Sciences,

Department of Otorhinolaryngology-

Head \& Neck Surgery, Kota Bharu,

Kelantan, Malaysia

az.aziz21@yahoo.com

R.H. Lo

ORCID: 0000-0001-7551-6544

N.K.N. Mohd

ORCID: 0000-0002-6011-3766

K. Abdullah

ORCID: 0000-0001-7171-8018

Hospital Sultanah Nur Zahirah, Department of Otorhinolaryngology, Kuala Terengganu, Terengganu, Malaysia

I. Mohamad

ORCID: 0000-0001-8572-0514 Universiti Sains Malaysia, Health Campus, School of

Medical Sciences, Department of Otorhinolaryngology-Head \& Neck Surgery, Kota Bharu, Kelantan, Malaysia 


\section{INTRODUCTION}

Lymphangiomas are rarely seen congenital benign malformations of the lymphatic system ${ }^{1}$. Management of the patient with lymphangioma is much more complicated than just simple excision as the lesion is often associated with a possible airway obstruction. Treatment of such lesion within a limited time and space during delivery makes the situation more challenging. As most of the congenital lymphangiomas can now be diagnosed during intrapartum period with advanced radiological techniques, EXIT (ex utero intrapartum treatment) procedure is one of the treatment options with improved maternal, and fetal outcomes.

\section{CASE REPORT}

A 22-year-old primigravida patient was referred to us at $20^{\text {th }}$ weeks of gestation after the antenatal USG showed fetus with abnormal neck swelling.

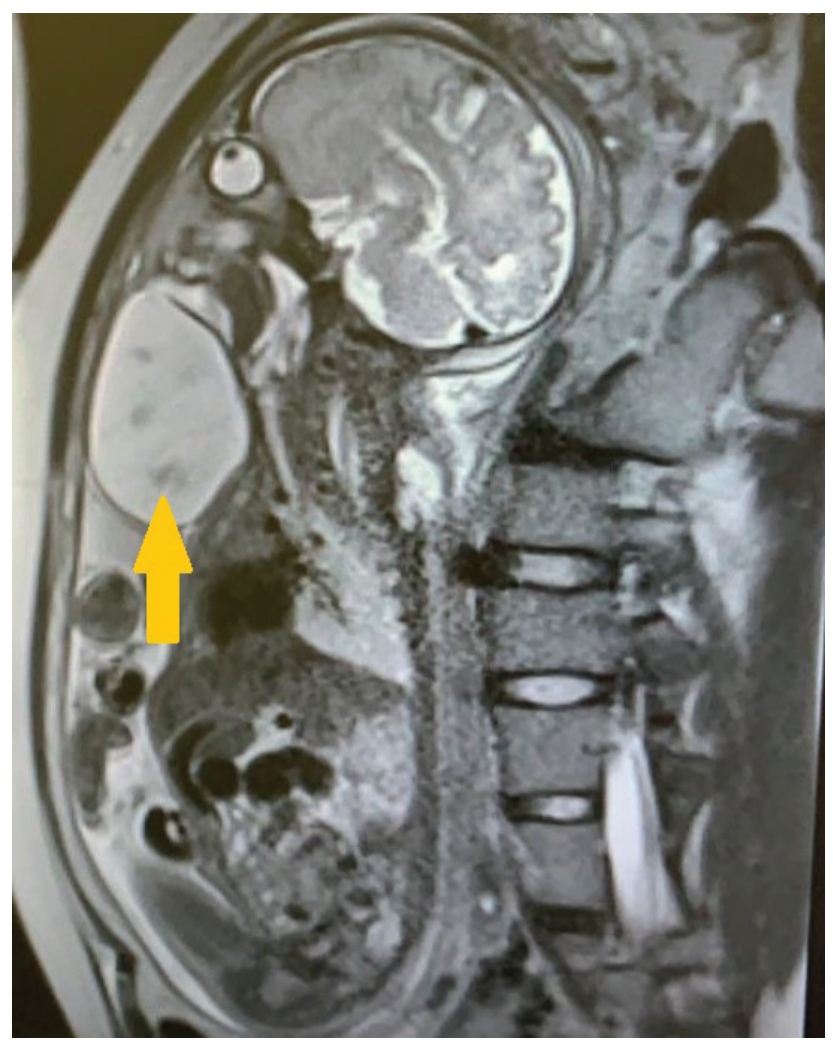

Figure 1. MRI showing fetus with extensive neck lymphangioma.
MRI demonstrated a huge multilobulated, multiseptated and predominantly cystic mass suggestive of lymphatic malformation involving the whole neck. No obliteration or compression of the fetal airway was shown (Figure1).

Multidisciplinary consultation was conducted with a team of pediatricians, obstetricians, otorhinolaryngologists (ORL) and anesthesiologists. Options of treatment and its potential complications were explained to the parents. Ex Utero Intrapartum Treatment (EXIT) procedure with intubation of the infant was planned.

EXIT procedure was done at 37 weeks of gestation. After a complete preparation and positioning of all team members, intubation of the mother was performed by an anesthesiology team. Obstetrician then proceeded with caesarean section. Infant's head with half of the neck mass was delivered through caesarean section, with its body in

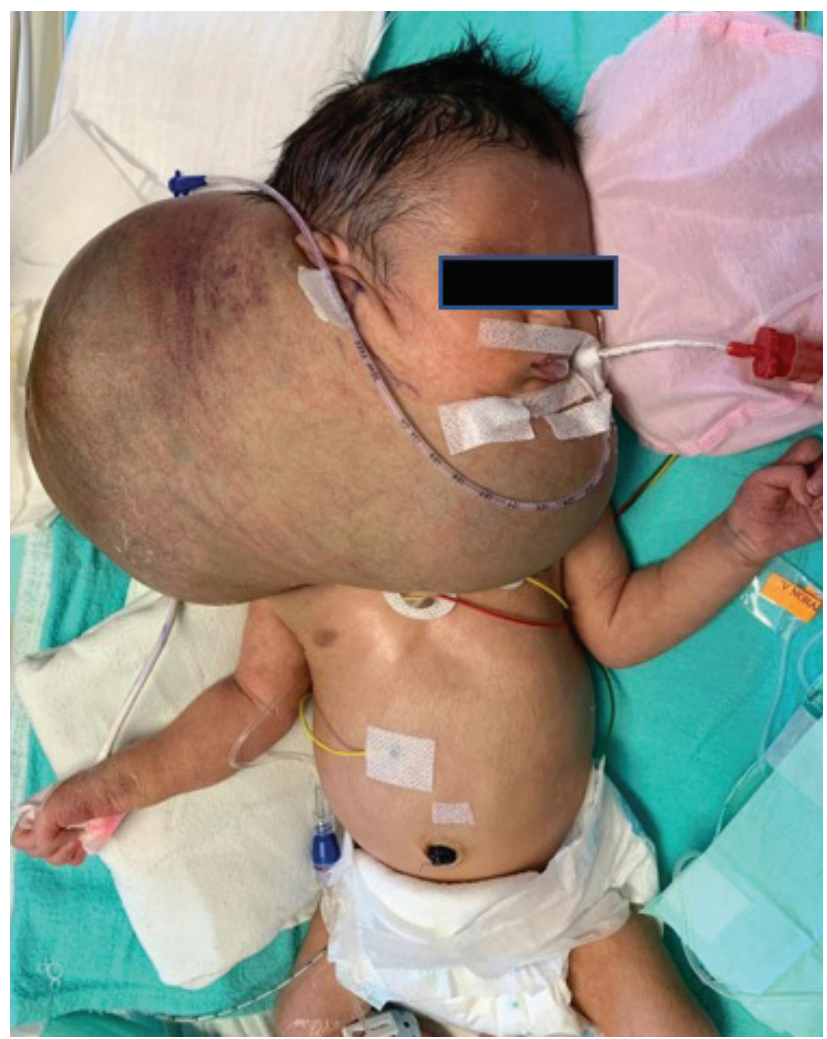

Figure 2. Patient with extensive right neck lymphangioma that crossing midline. 
utero to maintain fetal-maternal circulation. After permission from the pediatrician was obtained, direct diagnostic laryngoscopy was performed followed by securing airway with intubation of the infant. Infant was then delivered completely (Figure 2).

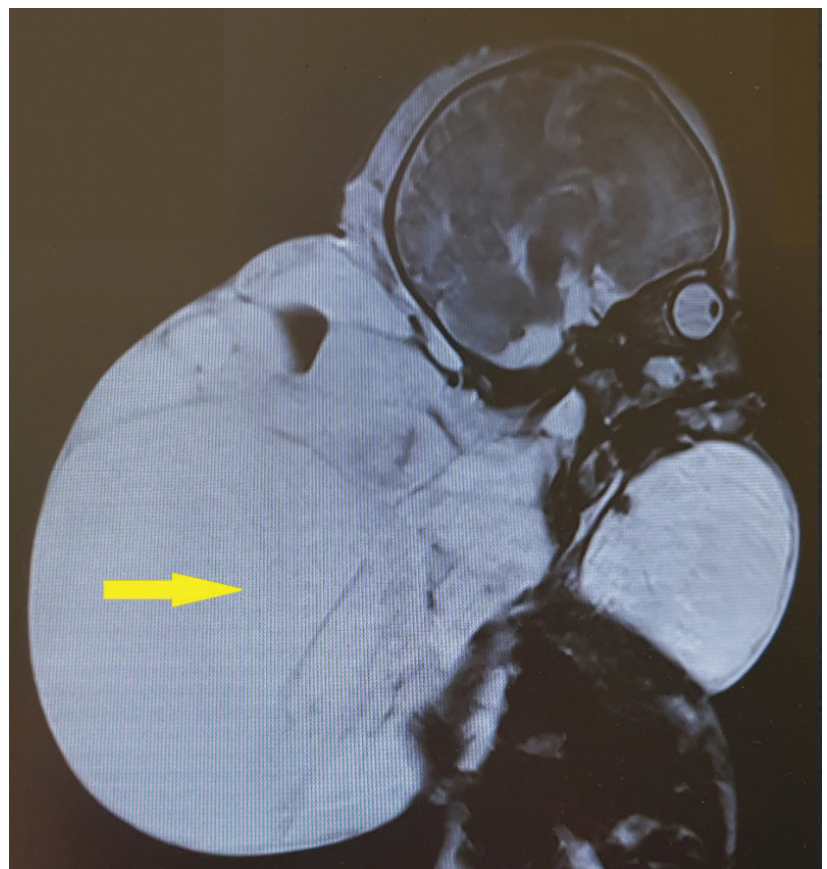

Figure 3. Postnatal MRI showing multilobulated multiseptated extensive neck lymphangioma.

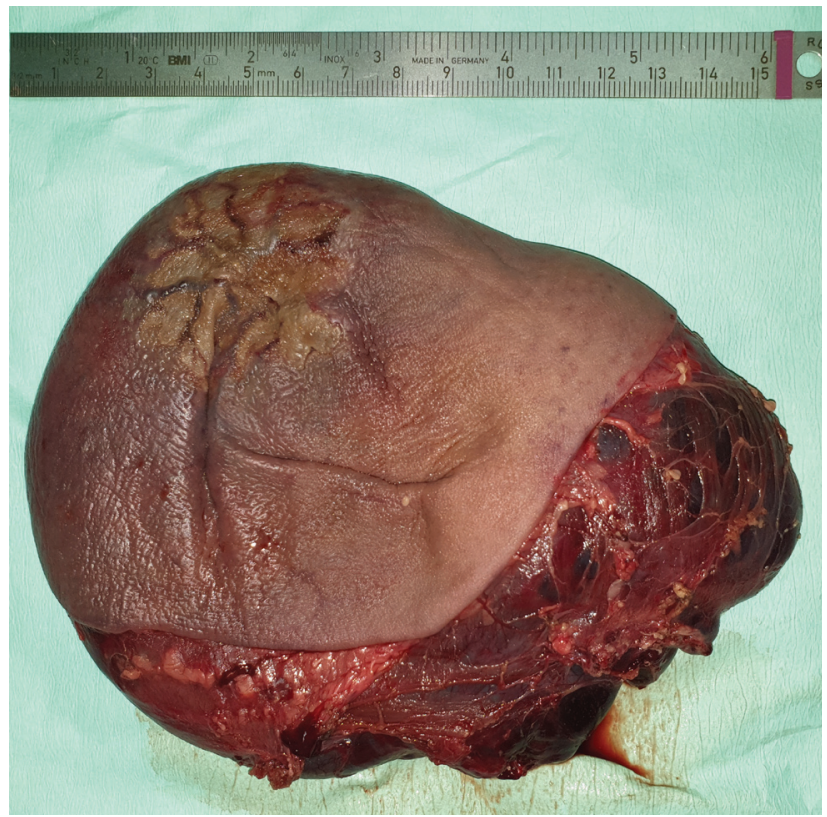

Figure 4. Excised tumour bulk.
Infant was kept ventilated and recurrent MRI examinations showed a $10.9 \mathrm{~cm} \times 24.8 \mathrm{~cm} \times 19.5$ $\mathrm{cm}$ multilobulated, mutiseptated lesion predominantly localized at right anterolateral neck encasing carotid arteries (Figure 3). Multiple fluid-fluid levels are seen within some locules suggestive of acute and subacute bleeding. Early excision was planned 3 days later after optimization of the infant's general well-being.

During operation, 3 cycles of disseminated intravascular coagulation (DIVC) regimen were performed. Swollen mass was removed successfully without injury to the vital structures (Figure 4,5). He was extubated 1 week later and subsequently discharged home well. Up to date, there has been

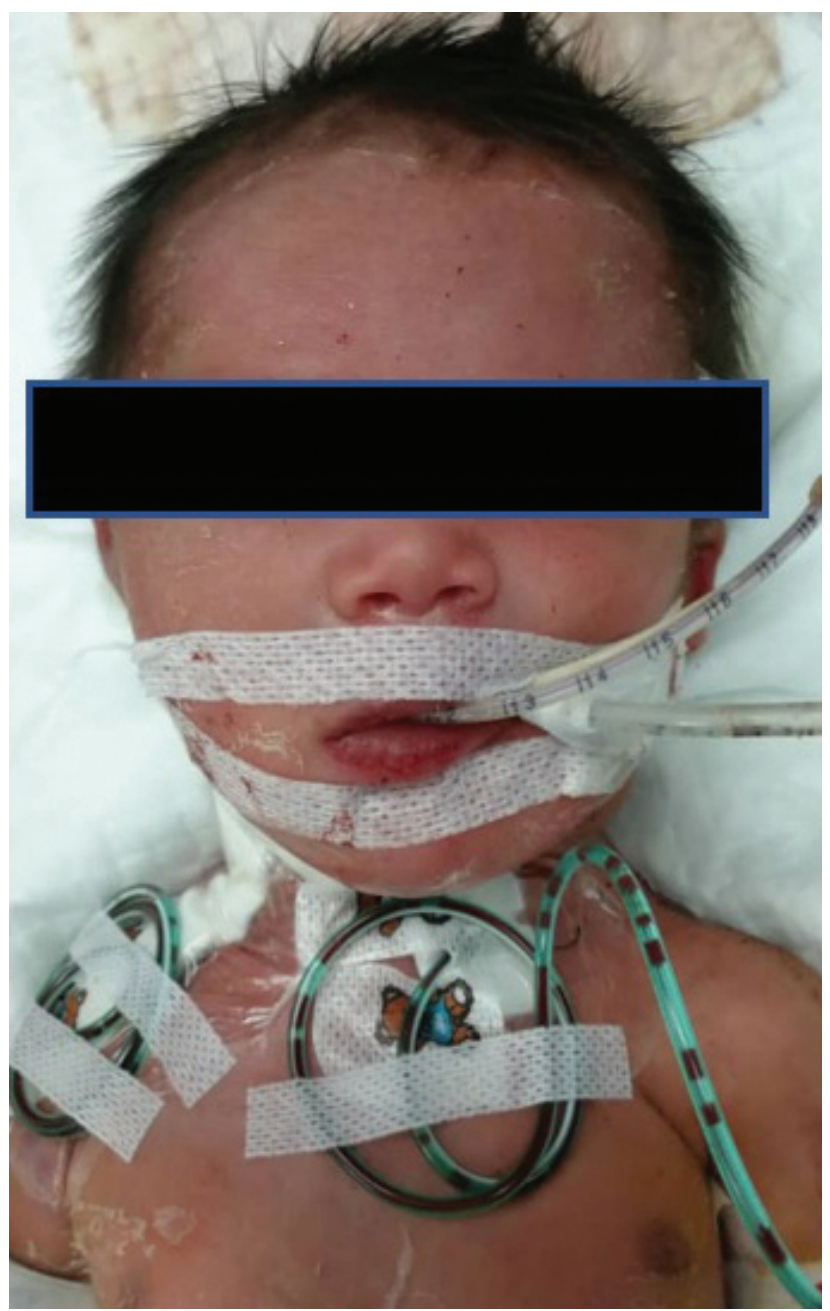

Figure 5. Post excision of neck lymphangioma. 
no recurrence of lymphangioma. Both mother and infant are doing well without any complications observed.

\section{DISCUSSION}

The management of intrapartum lymphangioma has been a challenging one ever since the mother presents to the hospital. Once the diagnosis of disease has been made, a multidisciplinary team including specialists from disciplines of pediatrics, obstetrics and gynecology, pediatric otorhinolaryngology, pediatric anesthesiology must be established. Before the counselling session with parents, whole team must have a detailed discussion on the prognosis of the fetus, treatment options, and possible complications.

Lymphangioma is possibly seen in Trisomy 13 , 18, 21, Turner Syndrome, Noonan Syndrome, and hydrops fetalis ${ }^{2}$. Obstetricians and pediatricians of the team must provide their expert opinion, regarding the prognosis and other associated organ diseases such as cardiac anomalies, gastrointestinal or genitourinary malformations of the fetus with the help of additional investigations.

For the treatment options, EXIT procedure, direct laryngoscopy with intubation keeping in view of tracheostomy was the best option in this case as MRI showed an extensive cervical lymphangioma. It is the treatment of choice for securing airway in fetus with gigantic neck masses that possibly compromised the airway ${ }^{3}$. Delivery at 37-38 weeks is recommended for the best fetal outcome $^{4}$. Spontaneous vaginal delivery is not an option here due to the disproportionate ratio between fetus with neck mass and vaginal introitus. Outcomes of EXIT regarding airway patency are generally dependent on underlying medical problems and degree of pulmonary hypoplasia ${ }^{5}$.

After realization of EXIT procedure has been agreed among the parents and the managing team, another meeting must be done to discuss regarding the best EXIT procedure schedule. Preparation of operating theatre (OT) is very important, as it is often difficult to accommodate all 4 groups of managing doctors working in the OT with their instruments. Only authorized personnel are allowed to enter the OT. Roles for each team member must be well specified. Rehearsal of the whole procedure is also an important phase for effective communication during the procedure.

Team must anticipate potential complications such as maternal cardiopulmonary instability, massive bleeding, or failure to establish patency of neonatal airway. In case of fetus with polyhydramnios or hydrops fetalis, a premature delivery might be tried. Parents are not advised to travel far from the planned tertiary hospital, to avoid unoptimized treatment in case of early delivery. Such complications must be foreseen and solution has to be pondered.

EXIT procedure is a treatment strategy that helps to establish neonatal cardiopulmonary support or definitive airway in a controlled setting ${ }^{5}$. It was first introduced in the early 1990s for the establishment of airway in a prenatally diagnosed oropharyngeal tumor with airway obstruction ${ }^{6}$. It converts an emergency airway condition into an elective-controlled situation.

Once mother is in the OT, preoperative USG is performed to assess the final position of both fetus and placenta to avoid injury to the placenta by the caesarean section which is crucial in uteroplacental gas exchange. General anesthesia is then given to the mother with adequate inhalational anesthetics for optimum uterine relaxation. Operation can start only after all teams are prepared and positioned.

During the procedure, obstetrician could only deliver fetus' head with part of the mass as the lesion was too big which partly restricted ORL surgeon's in manipulation of the fetus. Time frame for securing the airway is very narrow since the prolonged 
procedure will compromise fetal-maternal circulation due to uterine contraction. The anesthetist's role is very important at this moment who should provide uterine relaxation time necessary for the completion of the procedure. Prolonged uterine relaxation might cause postpartum hemorrhage. This could only be achieved with a perfect communication between each member of the managing teams.

The operation was uneventful, patient was able to be intubated with single attempt using endotracheal tube size 3.0 without complication. Umbilical cord was clamped. Inhalational anesthetics with tocolytics were stopped, and soon after medications for uterine contractions were administered. Fetus was delivered and further management would be taken over by pediatricians.

In our case, the infant's general condition deteriorated soon after birth, requiring double inotropes. MRI revealed the presence of a large lymphangioma with evidence of acute and subacute bleeding. Early excision of the mass warranted without trial of other treatment options. In view of the large tumour bulk, operation is likely to be time consuming. Prolonged operation might possibly affect patient hemodynamically. Quick surgery however is almost impossible due to the insinuating nature of the tumour to the surrounding vital structures, for which injury might cause a life-long morbidity. Thankfully, the surgery was successful without any major complications. During followup, he was doing well with no evidence of recurrence.

\section{CONCLUSION}

Lymphangioma of neck can be huge and may compromise the airway. It is worse if it is formed during intrapartum period, as birth can either be a life or death situation. EXIT procedure has significantly improved the survival of these patients, by giving more time for doctors to establish airway patency in a controlled setting. A multidisciplinary approach with proper preoperative planning is essential for the best outcome of the patient.

Acknowledgement: We would like to thank and acknowledge Miss Hashimah Ismail and $\mathrm{Mr}$ Suhaimi Yusuf for their supports in managing this case.

\section{REFERENCES}

1. Naidu SI, McCalla MR. Lymphatic malformations of the head and neck in adults: a case report and review of the literature. Ann Otol Rhinol Laryngol. 2004;113:218-22. [CrossRef]

2. Jaiswal AA, Garg AK, Ravindranath M, Sarkar J, Mohanty MK. A huge congenital cervical lymphangioma - Case report with review of literature. Egypt J Ear Nose Throat Allied Sci. 2015;16:283-90. [CrossRef]

3. Grosfeld LJ, O'Neill JA, Coran AG, Fonkalsrud EW. Pediatric Surgery: 2-volume Set. 6th ed. Mosby. 2006 p:213746.

4. Butler CR, Maughan EF, Pandya P, Hewitt R. Ex utero intrapartum treatment (EXIT) for upper airway obstruction. Curr Opin Otolaryngol Head Neck Surg. 2017;25:11926. [CrossRef]

5. Bence CM, Wagner AJ. Ex utero intrapartum treatment (EXIT) procedures. Semin Pediatr Surg. 2019;28:150820. [CrossRef]

6. Kelly MF, Berenholz L, Rizzo KA, Greco R, Wolfson P, Zwillenberg DA. Approach for oxygenation of the newborn with airway obstruction due to a cervical mass. Ann Otol Rhinol Laryngol. 1990;99:179-82. [CrossRef] 